\title{
Basic Minimal Total Dominating Functions of Quadratic Residue Cayley Graphs
}

\author{
S. Jeelani Begum \\ Associate Professor \\ Department of Mathematics, MITS, Madanapalle, \\ AP, INDIA.
}

\begin{abstract}
Domination theory is an important branch of Graph Theory and has many applications in Engineering, Communication Networks and many others. Allan, R.B., and Laskar, R., [1,2], Cockayne, E.J.,and Hedetniemi, S.T., [3], Haynes, T.W., and Slater, J.S., [4], have studied various domination parameters of graphs. Graphs associated with certain arithmetic functions which are usually called arithmetic graphs have been studied extensively by many researchers. In this paper we study the minimal total dominating functions and basic minimal total dominating functions (BMTDFs) of quadratic residue Cayley graphs and results on these functions are obtained. The theory of BMTDFs in quadratic residue Cayley graphs is an impulsive and methodical program that provides numerous interesting theoretical and computational aspects. It helps to study the related theory in other classes of graphs for further research and also improves the ability of work in some networks such as telecommunications, mobile applications etc.
\end{abstract}

\section{Keywords}

Quadratic Residue Cayley Graph, Minimal Total Dominating Function, Basic Minimal Total Dominating Function.

AMS (MOS) Subject Classification: 6905c

\section{INTRODUCTION}

\section{QUADRATIC RESIDUE CAYLEY GRAPH AND ITS PROPERTIES}

Let $\mathrm{p}$ be an odd prime and $\mathrm{n}$, a positive integer such that $\mathrm{n} \not \equiv 0(\bmod \mathrm{p})$. If the quadratic congruence $\mathrm{x}^{2} \equiv \mathrm{n}$ $(\bmod \mathrm{p})$ has a solution then $\mathrm{n}$ is called a quadratic residue modulo $\mathrm{p}$ and it is written as $\mathrm{nRp}$. If the congruence $\mathrm{x}^{2} \equiv \mathrm{n}(\bmod \mathrm{p}) \quad$ has no solution, then $\mathrm{n}$ is called the quadratic non-residue mod $\mathrm{p}$ and is written as $n \bar{R} p$.

Example 1: For the prime 11, we have

$1^{2} \equiv 1, \quad 2^{2} \equiv 4, \quad 3^{2} \equiv 9, \quad 4^{2} \equiv 5, \quad 5^{2} \equiv 3 \quad 6^{2} \equiv 3$,

$7^{2} \equiv 5, \quad 8^{2} \equiv 9, \quad 9^{2} \equiv 4, \quad 10^{2} \equiv 1(\bmod 11)$.

Consequently the quadratic residues mod 11 are $1,3,4,5,9$ and the non-residues are 2, 6, 7, 8, 10. Let $p$ be an odd prime, $S$, the set of quadratic residues modulo $\mathrm{p}$ and let $S^{*}=\{\mathrm{s}, \mathrm{p}-\mathrm{s} / \mathrm{s} \in \mathrm{S}, \mathrm{s} \neq \mathrm{p}\}$. The quadratic residue Cayley graph $\mathrm{G}\left(\mathrm{Z}_{\mathrm{p}}, \mathrm{Q}\right)$ is defined as the graph whose vertex set is the set of residue classes modulo $p$ i.e. $Z_{p}=\{0,1,2,3, . .,(p-1)\}$, and the edge set $\mathrm{E}=\left\{(\mathrm{x}, \mathrm{y}) / \mathrm{x}-\mathrm{y}\right.$ or $\mathrm{y}-\mathrm{x}$ is in $\left.\mathrm{S}^{*}\right\}$.

The graphs $\mathrm{G}\left(\mathrm{Z}_{7}, \mathrm{Q}\right)$ and $\mathrm{G}\left(\mathrm{Z}_{17}, \mathrm{Q}\right)$ are given below.

\author{
B. Maheswari \\ Professor \\ Department of Mathematics, \\ Sri Padmavati Women's University, Tirupati, AP, \\ INDIA
}
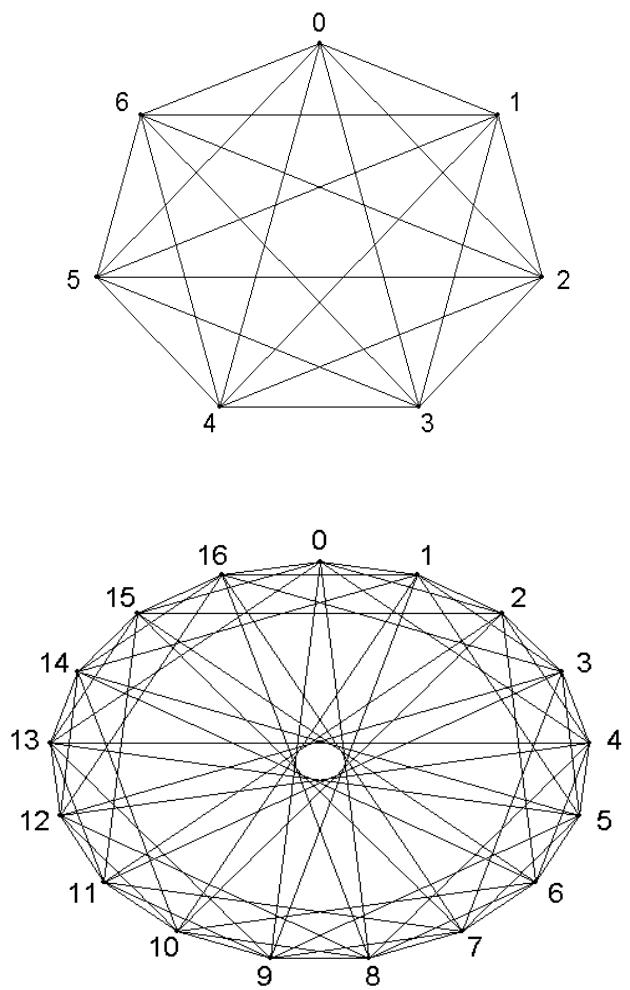

We make use of the following results whose proofs can be found in Madhavi [5 ].

Lemma 1.1: The graph $G\left(Z_{p}, Q\right)$ is $\left|S^{*}\right|$ - regular and the number of edges of $\mathrm{G}\left(\mathrm{Z}_{\mathrm{p}}, \mathrm{Q}\right)$ is $\frac{\left|Z_{p}\right|\left|S^{*}\right|}{2}$.

Theorem 1.2: The graph $G\left(Z_{p}, Q\right)$ is complete if and only if, $\mathrm{p} X\left(a^{2}+b^{2}\right)$, for any positive integers $\mathrm{a}$ and $\mathrm{b}$.

Theorem 1.3: The graph $G\left(Z_{p}, Q\right)$ is complete if $p$ is of the form $4 m+3$.

Theorem 1.4: If $p$ is of the form $4 m+1$, then the sets $Q$ and $\mathrm{S}^{*}$ are the same, so that the graph $\mathrm{G}\left(\mathrm{Z}_{\mathrm{p}}, \mathrm{Q}\right)$ is not complete.

\section{BASIC MINIMAL TOTAL DOMINATING FUNCTIONS}

Let $\mathrm{G}(\mathrm{V}, \mathrm{E})$ be a graph without isolated vertices. A function $f: V \rightarrow[0,1]$ is called a total dominating function (TDF) if $f(N(v))=\sum_{u \in N(v)} f(u) \geq 1$ for all $\mathrm{v} \in \mathrm{V}$. 
A TDF $\mathrm{f}$ is called a minimal total dominating function (MTDF) if for all $\mathrm{g}<\mathrm{f}$, $\mathrm{g}$ is not a TDF. A MTDF $\mathrm{f}$ of a graph is called a basic minimal total dominating function

(BMTDF) if $\mathrm{f}$ cannot be expressed as a proper convex combination of two distinct MTDFs.

Let $f$ be a TDF of a graph $G(V, E)$. The boundary set of $f$ is defined by

$$
B_{f}=\left\{u \in V / f(N(u))=\sum_{x \in N(u)} f(x)=1\right\} .
$$

The positive set of $\mathrm{f}$ is defined by

$$
P_{f}=\{u \in V / f(u)>0\} .
$$

We state the following theorems which are useful for obtaining subsequent results and the proofs of these theorems can be found in Rejikumar [6].

Theorem 1.5: Let $\mathrm{f}$ be MTDF of a graph $\mathrm{G}(\mathrm{V}, \mathrm{E})$ with $B_{f}=\left\{\mathrm{v}_{1}, \mathrm{v}_{2}, \ldots ., \mathrm{v}_{\mathrm{m}}\right\}$ and $P_{f}^{\prime}=\{\mathrm{u} \in \mathrm{V} / 0<\mathrm{f}(\mathrm{u})<1\}$ $=\left\{\mathrm{u}_{1}, \mathrm{u}_{2}, \ldots \ldots, \mathrm{u}_{\mathrm{n}}\right\}$. Let $\mathrm{A}=\left(\mathrm{a}_{\mathrm{ij}}\right)$ be an $\mathrm{m} \times \mathrm{n}$ matrix defined by

$$
a_{i j}=\left\{\begin{array}{l}
1, \text { if } v_{i} \text { is adjacent to } u_{j} \\
0, \text { otherwise. }
\end{array}\right.
$$

Consider the system of linear equations given by

$\sum_{j=1}^{n} a_{i j} x_{j}=0, \quad(1 \leq i \leq m)$.

Then $f$ is a BMTDF if and only if $\left(S_{2}\right)$ does not have a non-trivial solution.

Corollary 1.6: Let $\mathrm{G}(\mathrm{V}, \mathrm{E})$ be a graph without isolated vertices. Let $\mathrm{S}$ be a MTDS of G. Then $f=\chi_{S}$ is a BMTDF

\section{MAIN RESULTS}

Theorem 2.1: A function $f: V \rightarrow[0,1]$ defined by

$$
f(v)=\frac{1}{q}, \forall \mathrm{v} \in \mathrm{V}, \mathrm{q}>0 \text {, becomes a TDF of } \mathrm{G}\left(\mathrm{Z}_{\mathrm{p}}, \mathrm{Q}\right) .
$$

It is a MTDF if $\mathrm{q}=\mathrm{p}-1$, otherwise not a MTDF.

Proof: Suppose $p=4 m+3$. Consider $G\left(Z_{p}, Q\right)$ with vertex set $\mathrm{V}=\{0,1,2, \ldots \ldots . .(\mathrm{p}-1)\}$. Let $\mathrm{p}-1=\mathrm{m}$. Then every neighbourhood $\mathrm{N}(\mathrm{v})$ of $\mathrm{v}$ in $\mathrm{V}$ consists of $\mathrm{m}$ vertices. Let $\mathrm{f}$ be a function defined on $\mathrm{V}$ as in the hypothesis.

Case 1: Suppose $\mathrm{q}=\mathrm{m}$.

Then $f(v)=\frac{1}{m}, \forall \mathrm{v} \in \mathrm{V}$.
And $\sum_{u \in N(v)} f(u)=\frac{1}{m_{4}}+\frac{1}{42}+\ldots+\frac{1}{43^{m}}=\frac{m}{m}=1, \forall \mathrm{v} \in \mathrm{V}$.

Therefore $\mathrm{f}$ is a TDF.

We now check for the minimality of $f$.

Suppose $g: V \rightarrow[0,1]$ is a function defined by

$$
g(v)= \begin{cases}r, & \text { if } v=v_{k}, \\ \frac{1}{m}, & \text { if } v \in V-\left\{v_{k}\right\} .\end{cases}
$$

where $\mathrm{r}<1 / \mathrm{m}$ and $\mathrm{v}_{\mathrm{k}} \in \mathrm{V}$.

$$
\begin{aligned}
& \text { Then } \sum_{u \in N(v)} g(u)=\frac{1}{m^{n}}+\frac{1}{4 m_{2}}+\ldots+\frac{1}{43^{m}}+r \\
& <\frac{(m-1)}{m}+\frac{1}{m}=\frac{m}{m}=1 \text {. }
\end{aligned}
$$

Therefore $\sum_{u \in N(v)} g(u) \nsupseteq 1, \forall \mathrm{v} \in \mathrm{V}$.

So $g$ is not a TDF. Since $g$ is defined arbitrarily, it follows that there exists no $g<f$ such that $g$ is a TDF. Thus $f$ is a MTDF.

Case 2: Suppose $0<\mathrm{q}<\mathrm{m}$.

Then $\sum_{u \in N(v)} f(u)=\frac{1}{q}+\frac{1}{q 42443^{q}}+\ldots .+\frac{1}{q}$.

$$
\text { m-times }
$$

Since $\mathrm{q}<\mathrm{m}$, it follows that $\frac{m}{q}>1$.

Thus $\sum_{u \in N(v)} f(u)>1, \quad \forall v \in V$.

Therefore $\mathrm{f}$ is a TDF.

We now check for the minimality of $f$.

Define $g: V \rightarrow[0,1]$ by

$$
g(v)= \begin{cases}r, & \text { if } v=v_{k} \\ \frac{1}{q}, & \text { if } v \in V-\left\{v_{k}\right\}\end{cases}
$$

where $0<\mathrm{r}<\frac{1}{q}$ and $\mathrm{v}_{\mathrm{k}} \in \mathrm{V}$.

Since strict inequality holds at the vertex $v_{k}$ of $V$, it follows that $\mathrm{g}<\mathrm{f}$.

Then $\quad \sum_{u \in N(v)} g(u)=r+\frac{1}{q}+\frac{1}{4 q_{2} 4 . . .+43^{q}}$ 


$$
\leq \frac{1}{q}+\underset{4 \underset{m-\text { times }}{2}+\ldots . .}{\frac{1}{4}}+\frac{1}{q}=\frac{m}{q} .
$$

But $\frac{m}{q}>1$. So it follows that $\sum_{u \in N(v)} g(u)>1, \forall v \in V$.

This implies that $g$ is a TDF. Hence $f$ is not a MTDF in this case.

Theorem 2.2: A function $f: V \rightarrow[0,1]$ defined by

$$
f(v)=\frac{1}{q}, \forall \mathrm{v} \in \mathrm{V}, \mathrm{q}>0 \text {, becomes a TDF of } \mathrm{G}\left(\mathrm{Z}_{\mathrm{p}}, \mathrm{Q}\right) \text {. It }
$$

becomes MTDF if $\mathrm{q}=\left|S^{*}\right|$. Otherwise it is not minimal.

Proof: Suppose $p=4 m+1$. Consider $G\left(Z_{p}, Q\right)$ with vertex set $\mathrm{V}=\{0,1,2, \ldots \ldots . .(\mathrm{p}-1)\}$.

Then every $\mathrm{N}(\mathrm{v})$ of $\mathrm{v}$ in $\mathrm{V}$ consists of $\left|S^{*}\right|$-vertices.

Let $\left|S^{*}\right|=\mathrm{m}$. Let $\mathrm{f}$ be a function defined on $\mathrm{V}$ as in the hypothesis.

Case 1: Suppose $q=\mathrm{m}$.

Then $f(v)=\frac{1}{m}, \forall \mathrm{v} \in \mathrm{V}$.

And $\sum_{u \in N(v)} f(u)=\frac{1}{m^{2}}+\frac{1}{4 m}+\ldots+\frac{1}{43^{m}}=\frac{m}{m}=1, \forall \mathrm{v} \in \mathrm{V}$.

Therefore $\mathrm{f}$ is a TDF.

We now check for the minimality of $f$.

Suppose $g: V \rightarrow[0,1]$ is a function defined by

$$
g(v)= \begin{cases}r, & \text { if } v=v_{k}, \\ \frac{1}{m}, & \text { if } v \in V-\left\{v_{k}\right\} .\end{cases}
$$

where $\mathrm{r}<1 / \mathrm{m}$ and $\mathrm{v}_{\mathrm{k}} \in \mathrm{V}$.

If $\mathrm{v}_{\mathrm{k}} \in \mathrm{N}(\mathrm{v})$,

$$
\begin{aligned}
& \text { then } \sum_{u \in N(v)} g(u)=\frac{1}{m_{4}}+\frac{1}{42}+\ldots+\frac{1}{43^{m}}+r \\
& \text { (m-1)-times } \\
& <\frac{(m-1)}{m}+\frac{1}{m}=\frac{m}{m}=1 .
\end{aligned}
$$

If $\mathrm{v}_{\mathrm{k}} \notin \mathrm{N}(\mathrm{v})$, then $\sum_{u \in N(v)} g(u)=\frac{1}{m}+\frac{1}{4}+\ldots . .+\frac{1}{42}=\frac{m}{m}=1$.

But $\sum_{u \in N(v)} g(u) \nsupseteq 1, \forall \mathrm{v} \in \mathrm{V}$.

Therefore $g$ is not a TDF. Since $g$ is defined arbitrarily, it follows that there exists no $\mathrm{g}<\mathrm{f}$ such that $\mathrm{g}$ is a TDF.

Thus $f$ is a MTDF.

Case 2: Suppose $0<\mathrm{q}<\mathrm{m}$.

Then $\quad \sum_{u \in N(v)} f(u)=\frac{1}{q}+\frac{1}{q 424 . . .+\frac{1}{4}+3^{q}}=\frac{m}{q}$.

$$
\text { m-times }
$$

Since $\mathrm{q}<\mathrm{m}$, it follows that $\frac{m}{q}>1$.

Thus $\sum_{u \in N(v)} f(u) \geq 1, \quad \forall v \in V$. Therefore $\mathrm{f}$ is a TDF.

We now check for the minimality of $\mathrm{f}$.

Define $g: V \rightarrow[0,1]$ by

$$
g(v)= \begin{cases}r, & \text { if } v=v_{k}, \\ \frac{1}{q}, & \text { if } v \in V-\left\{v_{k}\right\} .\end{cases}
$$

where $0<\mathrm{r}<\frac{1}{q}$ and $\mathrm{v}_{\mathrm{k}} \in \mathrm{V}$.

Since strict inequality holds at the vertex $\mathrm{v}_{\mathrm{k}}$ of $\mathrm{V}$, it follows that $\mathrm{g}<\mathrm{f}$.

If $\mathrm{v}_{\mathrm{k}} \in \mathrm{N}(\mathrm{v})$,

$$
\text { then } \begin{aligned}
& \sum_{u \in N(v)} g(u)=r+\frac{1}{q}+\frac{1}{4 \underset{(m-1)-t i m e s}{4}+\ldots . .}+\frac{1}{q} \\
& <\frac{1}{q}+\frac{1}{q}+\ldots . .+\frac{1}{q}+\underset{m \text {-times }}{4} 43^{q}
\end{aligned}
$$

But $\frac{m}{q}>1$. So if $\mathrm{v}_{\mathrm{k}} \notin \mathrm{N}(\mathrm{v})$, then

$$
\sum_{u \in N(v)} g(u)=\frac{1}{q}+\frac{1}{4{ }_{\substack{m-\text { times } \\ 24}}^{4}+\ldots . .+\frac{1}{q}}=\frac{m}{q}>1 .
$$

$\Rightarrow \mathrm{g}$ is a TDF. So $\mathrm{f}$ is not a MTDF in this case. 
Theorem 2.3: The function $f: V \rightarrow[0,1]$ defined by $f(v)=\frac{1}{r}, \forall \mathrm{v} \in \mathrm{V}$ is a BMTDF in $\mathrm{G}\left(\mathrm{Z}_{\mathrm{p}}, \mathrm{Q}\right)$, where $\mathrm{r}$ denotes the degree of $\mathrm{v}$ in $\mathrm{V}$.

Proof: Consider the graph $G\left(Z_{p}, Q\right)$.

Case 1: Suppose $\mathrm{p}=4 \mathrm{~m}+3$.

Then $\mathrm{G}\left(\mathrm{Z}_{\mathrm{p}}, \mathrm{Q}\right)$ is a complete graph.

We know that $\mathrm{G}\left(\mathrm{Z}_{\mathrm{p}}, \mathrm{Q}\right)$ is $\left|S^{*}\right|$ - regular i.e., $(\mathrm{p}-1)$ - regular.

Let $\mathrm{p}-1=\mathrm{r}$. Let $\mathrm{f}$ be defined as in the hypothesis.

By Theorem 2.1, Case 1, $\mathrm{f}$ is a MTDF.

We now claim that $\mathrm{f}$ is a BMTDF.

Let $B_{f}=\left\{\mathrm{u}_{1}, \mathrm{u}_{2}, \mathrm{u}_{3}, \ldots, \mathrm{u}_{\mathrm{p}}\right\}, P_{f}^{\prime}=\left\{\mathrm{v}_{1}, \mathrm{v}_{2}, \mathrm{v}_{3}, \ldots, \mathrm{v}_{\mathrm{p}}\right\}$.

Here $B_{f}=P_{f}^{\prime}=V$.

Since $\sum_{u \in N(v)} f(u)=\frac{r}{r}=1, \forall \mathrm{v} \in \mathrm{V}$, we have $B_{f}=V$.

Similarly $0<\mathrm{f}(\mathrm{u})<1, \forall \mathrm{u} \in \mathrm{V}$, we have $P_{f}^{\prime}=V$.

Let $A=\left(a_{i j}\right)$ be a $p \times p$ matrix defined by

$$
\begin{aligned}
\mathrm{a}_{\mathrm{ij}} & =1 \text {, if } \mathrm{v}_{\mathrm{i}} \text { is adjacent to } \mathrm{v}_{\mathrm{j}}, \\
& =0 \text {, otherwise. }
\end{aligned}
$$

Then the system of linear equations associated with $f$ is defined by

$$
\sum_{j=1}^{p} a_{i j} x_{j}=0 \text { where } \mathrm{i}=1,2,3, \ldots, \mathrm{p} .
$$

Since every vertex $\mathrm{v}$ in $B_{f}$ is adjacent to all the $\mathrm{p}$ vertices of V we have $a_{i j}=1, \quad$ where $1 \leq \mathrm{i} \leq \mathrm{p}, 1 \leq \mathrm{j} \leq \mathrm{p}$.

The system of linear equations is given by

$$
\begin{array}{lccc}
\text { For } v_{1} \in B_{f}, & 0 . x_{2}+1 . x_{3}+\ldots+1 . x_{p}=0 \\
\text { For } v_{2} \in B_{f}, & 1 . x_{1}+0 . x_{3}+\ldots+1 . x_{p}=0 \\
\ldots & \ldots & \ldots & \ldots \\
\ldots & \ldots & \ldots & \ldots \\
\text { For } v_{p} \in B_{f}, & 1 . x_{1}+1 . x_{2}+\ldots+0 . x_{p-1}=0 .
\end{array}
$$

This is of the form $\mathrm{AX}=0$, which gives a trivial solution.

By Theorem 5, it follows that $\mathrm{f}$ is a BMTDF.

Case 2: Suppose $\mathrm{p}=4 \mathrm{~m}+1$.

Then $\mathrm{G}\left(\mathrm{Z}_{\mathrm{p}}, \mathrm{Q}\right)$ is $\left|S^{*}\right|$ - regular. Let $\left|S^{*}\right|=\mathrm{r}$.

Define a function $f: V \rightarrow[0,1]$ by $f(v)=\frac{1}{r}, \forall \mathrm{v} \in \mathrm{V}$.

By Theorem 2.2, Case 1, $\mathrm{f}$ is MTDF

We claim that $\mathrm{f}$ is not a BMTDF.
Here $B_{f}=V, P_{f}^{\prime}=V$, where $B_{f}=\left\{\mathrm{v}_{1}, \mathrm{v}_{2}, \mathrm{v}_{3}, \ldots, \mathrm{v}_{\mathrm{p}}\right\}$, $P_{f}^{\prime}=\left\{\mathrm{u}_{1}, \mathrm{u}_{2}, \mathrm{u}_{3}, \ldots, \mathrm{u}_{\mathrm{p}}\right\}$ say.

Then the system of equations associated with $\mathrm{f}$ is given by $\sum_{j=1}^{p} a_{i j} x_{j}=0$ where $\mathrm{i}=1,2,3, \ldots, \mathrm{p}$

where $\mathrm{A}=\left(\mathrm{a}_{\mathrm{ij}}\right)_{\mathrm{p} \times \mathrm{p}}$ is defined by

$$
\begin{aligned}
a_{i j} & =1, \text { if } v_{i} \text { is adjacent to } u_{j}, \\
& =0 \text {, otherwise. }
\end{aligned}
$$

Since every vertex $\mathrm{v}$ in $B_{f}$ is adjacent to $\mathrm{r}$ vertices of $\mathrm{V}$ we have $a_{i j}=1$ for $r$ variables where $1 \leq \mathrm{i} \leq \mathrm{p}, 1 \leq \mathrm{j} \leq \mathrm{p}$.

Then the system of equations $\mathrm{AX}=0$ has a trivial solution.

Thus by Theorem 1.5, it follows that $\mathrm{f}$ is a BMTDF.

\section{ILLUSTRATION}

Consider the graph $\mathrm{G}\left(\mathrm{Z}_{5}, \mathrm{Q}\right)$.

Since it is 2-regular, $\left|S^{*}\right|=r=2$.

Define a function $f: V \rightarrow[0,1]$ by

$$
f(v)=\frac{1}{r}=\frac{1}{2}, \forall \mathrm{v} \in \mathrm{V} .
$$

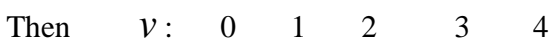

$$
\begin{array}{cccccc}
f(v): & \frac{1}{2} & \frac{1}{2} & \frac{1}{2} & \frac{1}{2} & \frac{1}{2} \\
\sum_{u \in N[v]} f(u): & 1 & 1 & 1 & 1 & 1
\end{array}
$$

Thus $\mathrm{f}$ is a MTDF.

Here $B_{f}=\{0,1,2,3,4\}=\mathrm{V}=P_{f}^{\prime}$.

The system of linear equations is given by

$$
\begin{aligned}
& \text { For } v_{1}=\mathrm{O} \in \boldsymbol{B}_{f}, x_{2}+x_{5}=0 \text {. } \\
& \text { For } v_{2}=1 \in B_{f}, x_{1}+x_{3}=0 \\
& \text { For } v_{3}=2 \in B_{f}, x_{2}+x_{4}=0 \text {. } \\
& \text { For } v_{4}=3 \in B_{f}, x_{3}+x_{5}=0 \\
& \text { For } v_{5}=4 \in B_{f}, x_{1}+x_{4}=0 \text {. }
\end{aligned}
$$

From (1) \& (3) we have $\mathrm{x}_{4}=\mathrm{x}_{5}$

From (2) \& (5) we have $\mathrm{x}_{4}=\mathrm{x}_{3}$

By (6) \& (7), $x_{3}=x_{5}$, and from (4) we get, $2 x_{3}=0 \Rightarrow x_{3}=0$. Therefore $\mathrm{x}_{1}=\mathrm{x}_{2}=\mathrm{x}_{3}=\mathrm{x}_{4}=\mathrm{x}_{5}=0$.

Thus the system of equations has a trivial solution. Hence $f$ is a BMTDF.

Lemma 2.4: Let $\mathrm{T}$ be a MTDS of $\mathrm{G}\left(\mathrm{Z}_{\mathrm{p}}, \mathrm{Q}\right)$. A function $f: V \rightarrow\{0,1\}$ defined by 


$$
f(v)=\left\{\begin{array}{l}
1, \text { if } v \in T, \\
0, \text { otherwise. }
\end{array} \text { is a BMTDF of } \mathrm{G}\left(\mathrm{Z}_{\mathrm{p}}, \mathrm{Q}\right) .\right.
$$

Proof: Since $\mathrm{f}$ assumes only the values 0 and $1, P_{f}^{\prime}=\phi$, and

by Corollary 1.6, it follows that $\mathrm{f}$ is a BMTDF.

\section{REFERENCES}

[1] Allan, R. B., and Laskar, R., On domination and independent domination number of a graph, Discrete Math , 23(1978), 73-76.

[2] Allan, R. B., Lasker.R., and Hedetniemi.S.T., A note on total domination , Discrete Math , 49(1984) 7-13.
[3] Cockayne, E.J.,and Hedetniemi, S.T., Towards a theory of domination in graphs, Networks, 7(1977), 247-261

[4] Haynes, T.W., Hedetniemi, S.T., and Slater, P.J., Fundamentals of Domination in Graphs, Marcel Decker, Inc . (1998).

[5] Madhavi L., Enumeration of Triangles and Hamilton Cycles in Quadratic Residue Cayley Graphs, Chamchuri J. Math. Vol.1(1), 95-103, 2009.

[6] Reji Kumar, K., Topological Properties of the Set of All Minimal Dominating Functions of Graphs, Proc. of ICDM 2006, Pages 249-254. 